\title{
Little Learning in Big Worlds
}

\author{
Jayson Cooper \\ Victoria University \\ jayson.cooper@vu.edu.au
}

Maureen Ryan

Victoria University

maureen.ryan@vu.edu.au

Keywords: community arts, learning communities, little aesthetics, little publics, international youth arts, public pedagogies, relationality

\begin{abstract}
Young peoples' worlds are valid and authentic spheres of knowing that communicate a range of issues. Through little aesthetics the artistic work in this project engages with what HickeyMoody (2014) terms 'little publics spheres' (p. 117). Artistic expression is one way for adults to engage with children's little public spheres. Situated within the larger field of public pedagogy little publics acknowledge the civic, social, economic, political worlds of young people. Through artistic re-presentations, we position little publics as a way to foster intercultural understanding and expression of self. The international collaboration between Gallery Sunshine Everywhere and Eritrean Australian Humanitarian Aid draws on the relational worlds of children through art. Drawings from two schools in Kassala, East Sudan were given to students at Flemington Primary School, Melbourne, who wrote evocative stories in response to the drawings. These little public expressions invite adult worlds into the intellectual presence of young people's perceptions and re-locate the roles of learner and teacher within and beyond structures of formal schooling. The concept of little publics validates children as important producers of culture, knowledge and learning contexts.
\end{abstract}




\section{What it means to me}

Figure 1: What it means to me: by Halima Idris and Thomas Nightingale

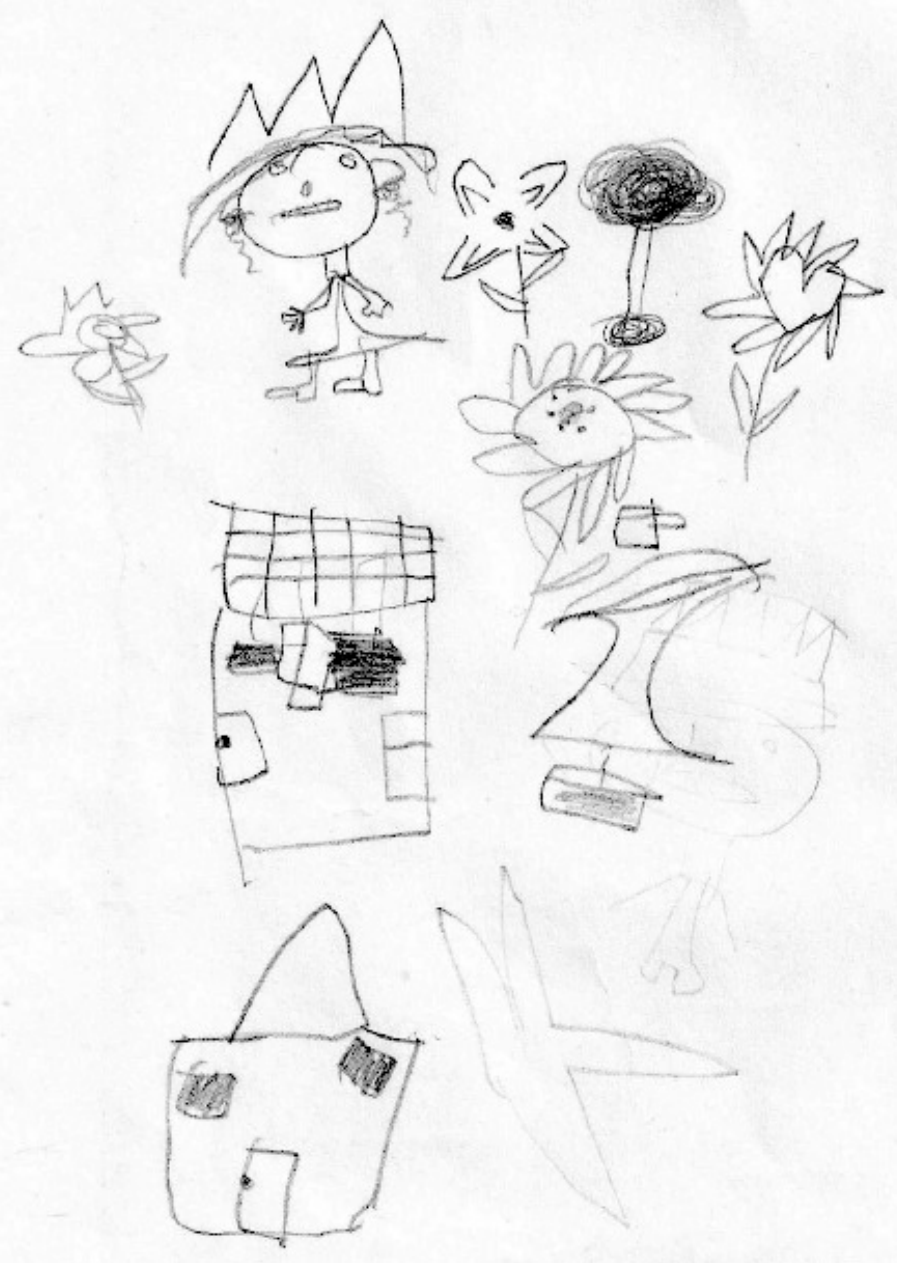

It looks like life the evolution of the world in small forms. It tastes like home, a sense of belonging like no other!! It feels like a new beginning of something great. It is always growing and adapting to the life of the world, giving gifts, being kind. Giving hope, life and a touch of magic. It's like a jigsaw: all the pieces make the puzzle, kindness makes an evolution. By working together you can do great things. A little help and a happy spirit and you are away. Work together, include everyone regardless of who they are. Life is a chain started by one followed by many people to make a world. Life is simple. Include. Be kind, help the world journey on. Why? Because you can make a difference. You can start or continue a chain like others have done before you. Show your emotions and be kind. That's what matters most. Bringing things together it forms happiness, all you have to do is work together and be kind. (Tartakover et al., 2015)

Drawing: Halima Idris, Nidal School, Kassala, East Sudan

Narrative: Thomas Nightingale, Flemington Primary School, Melbourne, Australia 


\section{Life is a chain started by one, followed by many people to make a world.}

This sentence awakens a rich and evocative perspective that is as vivid and brilliant as the art it depicts. Life is interconnected and significant; all we have to do is "be kind, help the world journey on". The sentiment communicated in the opening expresses the intertextual qualities of artistic expression and youth arts practice as democratic citizens in local and global communities. Diverse threads of communications indeterminately weave beautiful expressions of people's realities. Knight (2013) states the drawings done by young people are "subject to contextual influences" in how they are created, communicated, and understood, and that they are connected to encounters and events from daily life (p. 4) the mysterious and abstract qualities of arts practice created by children sometimes means adult audiences as 'outsider $\neg$ ' are closed to the deeper and complex encounters of meaning making across the physical and metaphysical aspects of a young person's life (Knight, 2013, p. 8). In this project, the barriers and boundaries of knowledge diminish within an international collaboration where children's worlds are prioritised and adult/child, north/south dichotomies are lessened. This paper highlights the ways partnerships validate youth voice by being inclusive of the published voices of children central to educational partnerships. All names, images and reference to the children artists is in relation to the publication they have been instrumental in creating. Particular permission was sought and acquired to use the children's names included in this work; celebrating the youth worlds and the exploration of artistic processes when discussing these worlds. A creative process that has been communicated beyond boundaries, and speaks 'techniques of relation' (Massumi, 2008) that enable a blurring of boundaries to inspire collective thinking.

Grade 4 student Thomas Nightingale from Flemington Primary School in Melbourne, Australia wrote the opening story. Written in response to the accompanied drawing prepared by Eritrean refugee Halima Idris in first class at Nidal School, Kassala, East Sudan. In this paper we draw upon the international collaboration between these two learning environments to celebrate and acknowledge the transformative and evocative ways youth are able to communicate artistically beyond boundaries.

The drawings and stories are part of the Words and Pictures Project (Tartakover et al., 2015), a collaboration between Eritrean Australian Humanitarian Aid (EAHA) and Gallery Sunshine Everywhere in Melbourne, Australia. EAHA chair, Anwar Alishek, collected children's drawings from two schools in Kassala, the capital city of the East Sudanese state of the same name. These drawings were given to children at Flemington Primary School, located in an inner city suburb of Melbourne. Children at Flemington wrote stories about and in response to the drawings. Curated by Sarah Tartakover and Maureen Ryan, a set of twenty drawings and accompanying stories were exhibited at Gallery Sunshine Everywhere in 2015. Alongside the twenty works were photographs by Anwar Alishek displaying school life in Kassala, and these images provided further context when engaging with the children's work. Subsequently, Debbie Qadri has reproduced the exhibited works in book form (Tartakover et al., 2015), intended as a resource for children in Kassala, Flemington and the Eritrean Australian Humanitarian Aid organisation (http://wordsandpicturesprojects.blogspot.com.au/). The possibilities for continued collaboration are wide ranging, including exhibitions and digital collections of the complete collection of materials gathered in this initial phase, further collections and avenues for children to communicate beyond borders, translated materials, pen pal links between the children, involvement of more schools in Kassala and in Melbourne, and an extension of this approach to include and work with schools in other parts of the world.

The collection of drawings combined with poetic narratives merged together to create powerful visual literacies that look and feel "like life; like the evolution of the world in small forms". Small forms: holistic and relational to larger forms that are again relational to even larger global forms. These little aesthetics ${ }^{1}$ (TISM, 1989) are reflective mirrors of adult and youth worlds 
and in the artistic work illustrated here, a powerful means of building and sharing intercultural understanding, community enrichment, and identity construction through multi-lingual forms of artistic and aesthetic knowing and communication. In this way the collection of artistic work discussed, engages with what Hickey-Moody (2014) terms "little publics" (p.117).

Figure 2: The Little Girl's Flower: by Hazir Mohamed Osman (year 7) and Issy Corcoran (Grade 4)
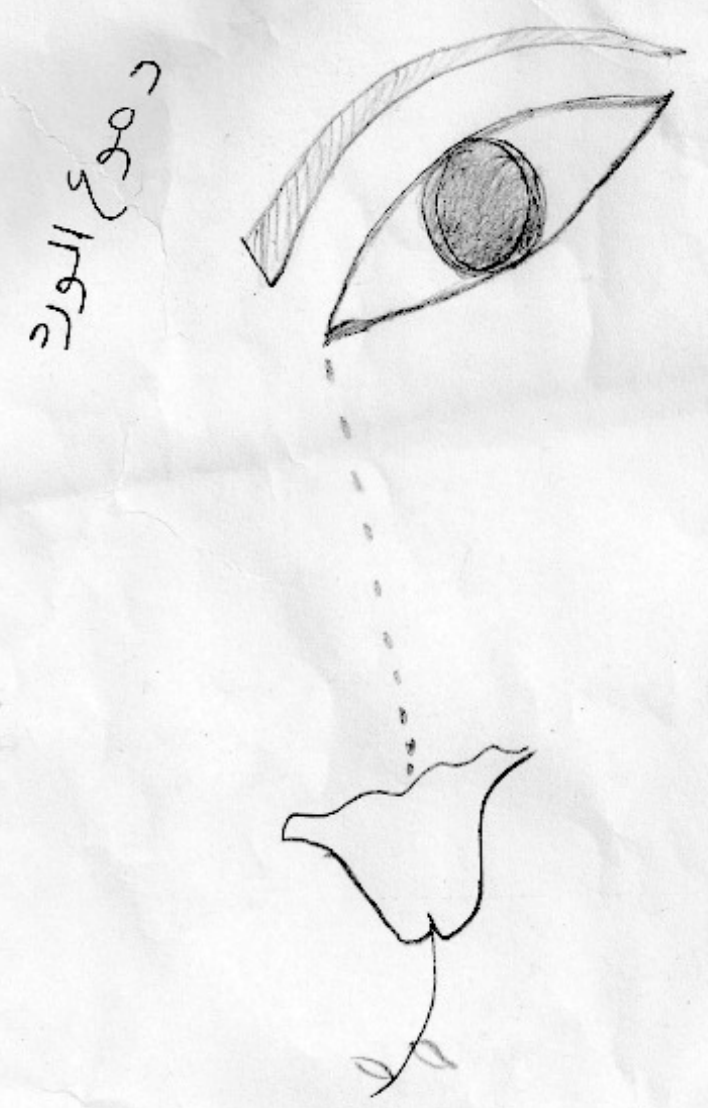

there was a little girl. She loved one flower. It was a majestic purple flower and she loved it very much. One day her father was digging up land and 'No Daddy, no' shouted the little girl running as fast as she could. But it was too late. He had already shovelled it into the compost heap. The little girl cried 1,000 tears. But, one tear touched the root of the purple flower. It started to grow before her eyes. Soon it was a fully grown purple flower and it survived for the rest of her life. (Tartakover et al., 2015)

Drawing: Hazir Mohamed Osman (year 7) Kassala, East Sudan

Narrative: Issy Corcoran (Grade 4) Flemington Primary School, Melbourne, Australia

1. TISM (This is Serious Mum) were an Australian band from Melbourne, Australia. Famous for their controversial songs and anonymous identities, in the early 1990's TISM released a book titled 'The TISM guide to little aesthetics: based on the works of This Is Serious Mum'. The title being a pun on an Australian physical education program called 'Little Athletics'. The book was not published for very long and was also controversial, raising legal issues with its publication. Mostly sold at TISM concerts this text is now a highly sought after piece of Australian popular culture. 
Through experiential artistic encounters a shared aesthetic-a shared little aesthetic $\neg-$ generates and communicates children's worlds, as educators we perceive a strong relationality between teaching and learning and teachers and learners and in this way we afford selfefficacy to the creators of the multimodal texts discussed in this paper. These voices together create 'little public spheres' that talk their positions within civic, social, cultural and political everyday lives. Little publics, Hickey-Moody (2014) argues, are as valid as the public worlds adults inhabit and occupy, and need to be taken as seriously. Aligned with the growing field of public pedagogy (Sandlin, Schultz, \& Burdick, 2010), little publics emphasise the transformative power of pedagogical interactions within shared spaces. Due to the broad range of meanings associated with the term public pedagogy scholars in the field have considered the problems and challenges within the discipline in order to transform and cultivate the spirit of public pedagogy (Burdick, Sandlin, \& O'Malley, 2014). Part of this revitalisation in theorising and enacting public performances is how the pedagogical lives and functions in the public domain. Framing the public in this way has to include the voices and civic contributions of children and adolescents, the progenitors of little publics; shaping and designing their private and public realities, worldviews, opinions, social interactions, cultural expressions and ethics.

Savage (2014) communicates his concerns about what constitutes the public, and urges public pedagogues to clearly state 'which public' and 'whose public' asking the question how is the pedagogical found within the everyday, 'which' everyday, and 'whose' everyday? The Eritrean and Australian collaboration resides in plural localities that are connected in rhizomatic and intertextual ways: following an array of possibilities and multiplicities. Savage highlights three general forms of public: political, popular, and concrete (p. 80). Each form of publicness is relational to its sphere of influence, scale, and context. Actions found within the concept of little publics are smaller in scale but mirror larger forms of the public to which they belong. In this way the public spheres made by young people can be political, popular, and concrete (Hickey-Moody, 2014). Savage (2014) reminds people who analyse the pedagogical in the concrete realm to be mindful of which and whose public we are referring to and the ways it ostensibly educates individuals enmeshed' in the creation of the pedagogical and the public (p. 88). Little public pedagogues choose how they co-create their public spheres in negotiation with adults as required, and at times can fall into contradiction and conflict with adult ideologies. Interactions that arise from young people's expression are not always predetermined but rather can be seen to be indeterminate and deeply involved in processes that are holistically woven together, "It's like a jigsaw: all the pieces make the puzzle" (Knight, 2013, p. 8).

Several theorists and researchers have located children and young people in the public pedagogies space. Pelosi (2015) writes of their active engagement with an annual arts event in a local botanical garden and draws on Ellsworth (2005) in her analysis of the Paint the Gardens event. As Ellsworth notes, "a staged public event becomes pedagogical and pedagogy becomes a public event when, together, they create a space between what reforms both the self and the other, the self and its lived relations with others" (p.48). Art provides a powerful means though which children and young people can engage in the world. Beyond sharing their ideas and their stories in public displays and developing enhanced self esteem through the complimentary responses they receive, there are opportunities for critique, explanation, responses to questions, reconsideration and future planning. 
Each of these skills is apparent in the Walking Neighbourhood project (http://thewalkingneigh bourhood.com.au/) where children are the guides for curated city tours. In their Walking Neighbourhood research, Phillips (2013) has investigated children's perceptions and interests in public spaces and have highlighted the potential that this approach has to extend understanding and practice of citizenship and democracy, core components of Giroux's (2003) definitions of public pedagogies. In their example of a walk led by one child they note his capacities for selecting a healthy burger venue as a base for the walk, negotiating two for one deals in a café and for donating to charity, and importantly for articulating the intent of his practice to his group. Another child focussed her walking tour on bookshops and public art exhibits while also sharing her own poems with her group.

These two examples of ways in which children can function in public spaces are extended further in Williams (2015) account of the Chilean student movement, utilising arts based methodologies while delivering the strongest possible messages about the role of the Chilean education system. Challenging, disrupting and making social and economic inequalities visible the student movement in Chile re-thinks how young people perceive and voice their present day and future educational, social, and political selves. The young are taking to the streets for a number of reasons and it is highly empowering interconnecting roles between learner and teacher. The blurring of teacher/learner relationships articulates diverse conceptions of public spaces and is far from being adult driven. Children teach and learn in unique and divergent ways, across political, popular and concrete public places as they walk the streets to revolutionise inequalities; to speak about their families and the important things in their lives, or to gently teach heartfelt knowledge about places that carry meaning in interactive and productive ways (Hickey \& Phillips, 2013).

\section{Giving hope, life and a touch of magic}

Gallery Sunshine Everywhere (www.gallerysunshine.com) was established in 2007 and has held close to one hundred exhibitions since then of pre-primary, primary and secondary school student artwork. The curated exhibitions combine the formality of the work being framed and openings held for each exhibition with the accessibility of the exhibitions being held in a local café in Sunshine (a suburb in western Melbourne). In an exhibition last year for Neighbour Day, visitors to the café could ponder the different perceptions of kindergarten children who displayed a strong focus on family, primary school children expressing social realities and friendships, and the less joyful images of the secondary students, highlighting fears and concerns they had for their neighbourhood.

As a young person grows into their community, their worldly perceptions and thoughts change and grow, the interconnections between youth, adults and the wider community give significant insights into how young people see the world around them. In this way the little public sphere promotes pedagogical encounters offered by young people. Hickey-Moody (2015) notes these learning entanglements are dualistic and pedagogical through "the cultural process of making a text", and as these cultural texts, "disseminate the aesthetics, values, politics and narratives developed through the cultural pedagogy of group process" (p. 79). Gallery Sunshine Everywhere has provided many opportunities to enhance the public pedagogue roles that young people can play within their communities. Often combining textual literacies such as drawing, painting and collage, children and young people can articulate the complex issues in ways that are truly arresting. 
Figure 3: One Thousand Boxes

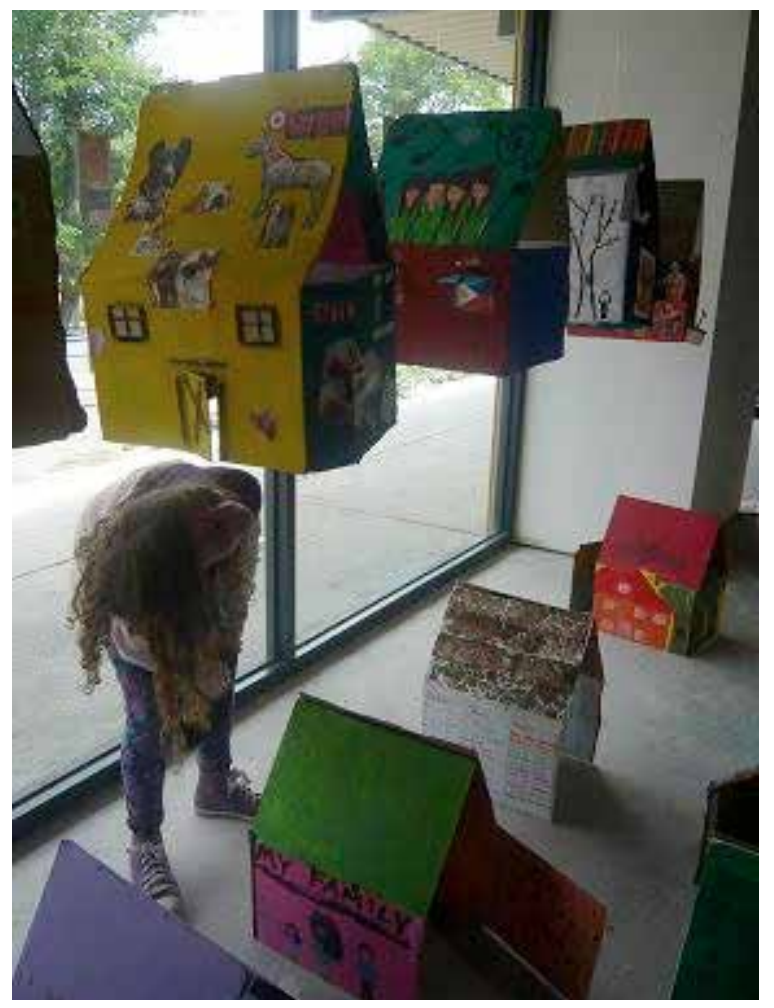

In another Gallery Sunshine Everywhere Project, 1,000 cardboard boxes were turned into houseboxes; colourful, imaginative, magical and lantern like, they captured hearts and imagination, highlighting love, peace, freedom, and revealing favourite poets, love of reading, preferences for rugby, bike riding and camping, for the beach, AFL teams, music, gymnastics, Little Athletics, dancing (especially rap), soccer, motorbikes, computers, scooters, guides, shopping, bikes, choir, television, tennis, films, toys, cross country, animals, maths, cricket, books, horse riding, netball, karate, pottery, swimming, gardening, badminton, basketball, ballet, Lego, car racing .......

Figure 4: One Thousand Box neighbourhood

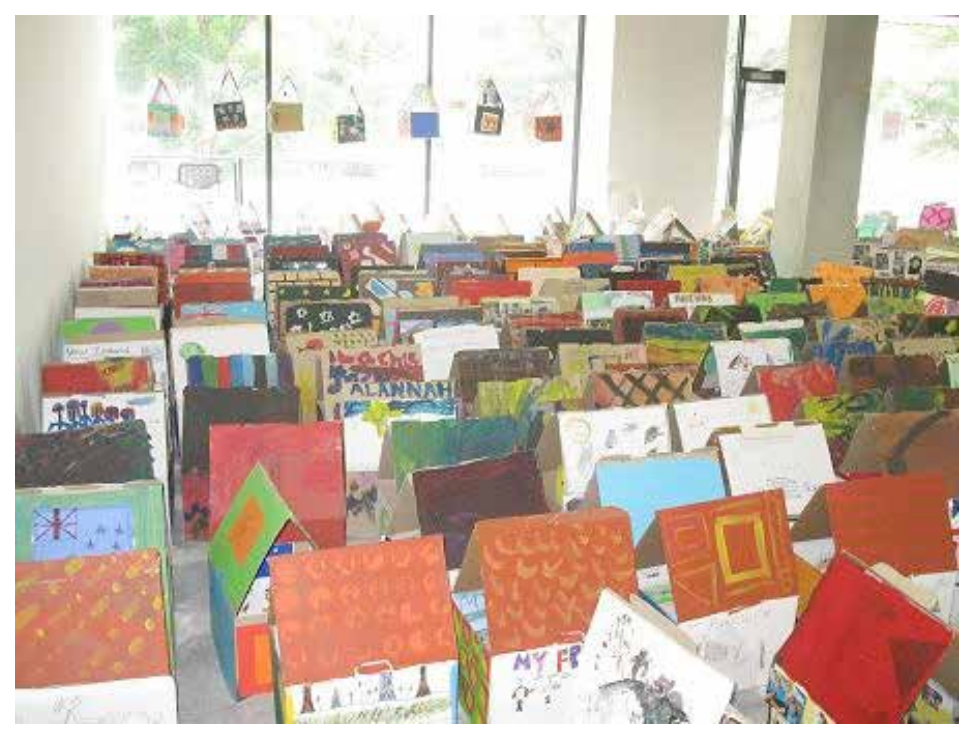


They told us about school uniforms, friends, zodiac signs, flags, religion, food, languages, national costumes, family celebrations, festivals, recipes and being "best at day dreaming and being silly". They described family backgrounds including Indigenous Australians and tales of grandparents who met on trams, went to war, travelled to Australia as refugees and from many countries: Cambodia, Chile, China, Croatia, Denmark, Egypt, El Salvador, England, Eritrea, Germany, Ghana, Greece, Holland, Hong Kong, Hungary, India, Indonesia, Iran, Ireland, Italy, Japan, Korea, Laos, Latvia, Lebanon, Macedonia, Malta, New Zealand, Papua New Guinea, Pakistan, Philippines, Poland, Romania, Russia, Samoa, Scotland, Serbia, Seychelles Islands, Sri Lanka, Sudan, Syria, Thailand, Timor Leste, Turkey, Ukraine, Vietnam and more.

The boxes provided a picture of the rich diversity of Brimbank (the local council area in which Gallery Sunshine Everywhere is based). In this project, local artist Mirjana Vuk-Nikic encouraged participants to share their community lives (usually on the outside of the boxes) and their family lives (usually inside the boxes). As Mirjana explained the project:

\begin{abstract}
Moving from one place to another is our past and our future. Figuratively, the family home is a big moving box. Inside this moving box is a family story and culture. Outside the moving box is a family's relation to the new community. When walking on the streets we cannot reach all these family stories and cultures behind the house walls. These stories and cultures are our treasure. Through sharing stories and cultural richness we learn about each other and how to live and grow in our communities. I chose a post box for making houseboxes because the post box symbolises sending items from one place to another. It makes connection from one city to another, from one country to another, from one culture to other, from one person to another person.
\end{abstract}

\title{
By working together you can do great things
}

The arts offer unique poetics of knowing, being and doing in education and community development; they are vibrant, diverse and immense, just like the communities they are connected to. They weave rich tapestries that unite people within and across places; they share what is common and what is culturally unique. Fashioning heterogeneous opportunities that can enable rich learning well situated away from hegemonic learning formulas. In counterpoint the arts provide openings for the unknown to become familiar, bubbling and slipping into the unplanned, the improvised, producing graceful and awkward connections. The arts provide a living, breathing fabric of expressions and reflections, woven by our collective hands telling ourselves and others around us how we value, know, act and are in the macrocosmic and microcosmic worlds we breathe life from. It is with these imaginative methods that communities are enriched; children become the producers of knowledge, the producers of their learning, rather than passive consumers.

The arts foster human development and are intrinsically linked to how we re-present history, the present moment, historical and contemporaneous cultural worldviews and how we perceive, imagine and process our realities. Art is a means in which we can hold a mirror to our humanity, a vehicle of communication that incites knowing and being from the aesthetic, it is a powerful way to transfer knowledge. The power of the arts is recognised as providing valuable experiences that enhance and enrich learning (Eisner, 2004). Grounded in a social constructivist Vygostkian stance, Ewing (2011) defines learning as consisting of a series of developments and growth in understanding and/or behaviour, 'facilitated by social, collaborative processes embedded in particular socio-historical-cultural contexts' (p. 33). Qadri (2015) offers an example of such processes in Memories in Motion, an account of a project linking primary school children and the rich history of the railway line adjacent to their school as it underwent its latest upgrade: 
The project incorporated the local history of the space between Sunshine Primary School and Sunshine station with students taking on the roles of the researchers/ historians of this place. History was regarded as a fluid entity, which was continually evolving, and being made. Gathered through primary and secondary evidence it also included the recording of memories. The students documented, researched and introduced their own memories and observations to make new renderings of history. Their work was "published" as artworks in public space and also in a book, which was placed in the school and local Sunshine library. (Qadri, 2015, p. 383)

The learning that is evolving from Gallery Sunshine Everywhere's Words and Pictures project - done in collaboration with the Eritrean Australian Humanitarian Aid - is a sound example of how the creative arts invoke the world of little publics, the world of children, together. Uniting people in a relational way to "form a shared event, a connection, to reach beyond and connect with singularities rather than be directed through rationalist hegemonic templates that encourage robotic" constructions (Knight, 2009, p. 8). Opening transformative and reciprocal arts learning for Eritrean and Australian communities allows intercultural "understandings of ourselves, our relationships with others and with the natural world" (Ewing, 2011, p. 33). These connections continue to develop and do great things as part of this ongoing project as young people are given creative licence over the artful encounters.

Positioning young people as the drivers of cultural expression we see it essential to allow the creators control over their creative practices and processes. In this way, the youth are the creators, the storytellers, the educative agents within civic, political, environmental, and educational commentaries and re-presentations. Adults are relational to this learning and our roles are contextual, depending on the proximity and relatedness to the artistic collective: as a parent/guardian/sibling, educator, artist, or wider audience member ${ }^{2}$. Herein lie the aesthetic diamonds that illuminate the interconnectedness between young and old, creators and audiences, where cultural meanings are fluidly articulated through the production of creative texts that "become pedagogical" (p. 82). The concept of little publics (Hickey-Moody, 2015) validates children as important producers of culture as well as valuing the intimate expressions of "informal, unbounded, culturally mediated and subjective learning" that flows from their pedagogical spaces (p. 82).

In alignment with formal Australian education requirements, the young people involved in this project engaged in aesthetic reasoning and artistic expression using a range of media and skill sets that are interdisciplinary. Utilising visual and language arts, children communicated to each other about their realities in that moment in time. These artistic conversations embrace what Maoz (2006) terms a mutual gaze. In each location these artistic conversations perform a mutual gaze through an experiential moment in a young person's life. Learning moments articulated through artistic expression. Opening possibilities for meaning making and understanding to organically grow and elicit reasoning, holistic perceptions and interactions. These move us into performative states: 'leaning' in towards, or away aesthetically (Pelias, $2011 ; 2014)$, embracing strong mutual gazes across continents, and across concepts of the public. The Eritrean little public, the Flemington little public, the combined international little public and the outward ripple effects of these pedagogical forces into larger publics. It is because of these creative actions that we are able to write from this adult perspective, to cast an educative lens over the actions of the little public sphere in order to celebrate the arresting qualities of young people's minds.

2. Audience refers to members of the larger public sphere who interact with the creative work and visual storytelling of the children artists. It can also refer to any person who is not part of the youth arts collective, in Sudan, Australia and now through your eyes reading this, wherever you are globally and contextually to this large public sphere. 
Life is simple. Include. Be kind, help the world journey on. Why? Because you can make a difference. You can start or continue a chain like others have done before you. Show your emotions and be kind. That's what matters most. Bringing things together it forms happiness, all you have to do is work together and be kind. (Tartakover et al., 2015)

\section{Acknowledgements}

Particular permission was sought and acquired to use the children's names included in this work as part of the Word and Pictures collaboration. 


\section{References}

Burdick, J., Sandlin, J.A., \& O'Malley, M.P. (2014). Problematizing public pedagogy. New York: Routledge.

Eisner, E. (2004). What can education learn from the arts about the practice of education. International Journal of Education \& the Arts, 5(4), 1-12.

Ellsworth, E. (2005). Places of learning: Media, architecture, pedagogy. New York: Routledge.

Ewing, R. (2011). The Arts and Australian Education: Realising Potential. Australian Education Review No. 58. Australian Council for Educational Research.

Giroux, H.A. (2003). Public pedagogy and the politics of resistance: Notes on a critical theory of educational struggle. Educational Philosophy and Theory, 35(1), 5-16.

Hickey, A., \& Phillips, L. (2013). New Kids on the Block: young people, the city and public pedagogies. Global Studies of Childhood, 3(2), 115-128.

Hickey-Moody, A. (2014). Little Public Spheres. In J. Burdick, J.A. Sandlin \& M.P. O’Malley (Eds.), Problematizing public pedagogy (pp. 117-129). New York: Routledge.

Hickey-Moody, A. (2015). Little publics and youth arts as cultural pedagogy. In M. Watkins, G. Noble \& C. Driscoll (Eds.), Cultural Pedagogies and Human Conduct (pp. 78). New York: Routledge.

Knight, L. (2009). Desire and rhizome: affective literacies in early childhood. In D. Masny \& D.R. Cole (Eds.), Multiple Literacies Theory: A Deleuzian Perspective. Rotterdam, The Netherlands: Sense Publishers.

Knight, L. (2013). Not As It Seems: using Deleuzian concepts of the imaginary to rethink children's drawings. Global Studies of Childhood, 3(3), 254-264.

Maoz, D. (2006). The mutual gaze. Annals of Tourism Research, 33(1), 221-239.

Massumi, B. (2008). The thinking-feeling of what happens. Inflexions, 1.1. Retrieved from http:// inflexions.org/n1_The-Thinking-Feeling-of-What-Happens-by-Brian-Massumi.pdf.

Pelias, R.J. (2011). Leaning: A poetics of personal relations. Walnut Creek, CA: Left Coast Press.

Pelias, R.J. (2014). Performance : An Alphabet of Performative Writing. Walnut Creek, CA. Left Coast Press.

Pelosi, L. (2015). Reaching for the arts in unexpected places: public pedagogy in the gardens. Australian Journal of Adult Learning, 55(3), 408.

Phillips, L. (2013). Text Talk by Children. On the street: Primary children's personal literacies. Practically Primary, 18(2), 24-26.

Qadri, D. (2015). Memories in Motion: learning, process, history and art in public space. Australian Journal of Adult Learning, 55(3), 379.

Sandlin, J.A., Schultz, B.D., \& Burdick, J. (2010). Handbook of public pedagogy: Education and learning beyond schooling. New York: Routledge.

Savage, G. (2014). Chasing the Phantoms of Public Pedagogy. In J. Burdick, J.A. Sandlin \& M.P. O'Malley (Eds.), Problematizing public pedagogy. New York: Routledge.

Tartakover, S., Ryan, M., \& Alishek, A. (2015). Words and Pictures. Footscray: College of Education, Victoria University. 
TISM. (1989). The TISM guide to little aesthestics: based on the works of This Is Serious Mum. Melbourne: Stock, Aristotle \& Waterman.

Williams, J. (2015). Remaking education from below: the Chilean student movement as public pedagogy. Australian Journal of Adult Learning, 55(3), 496-514.

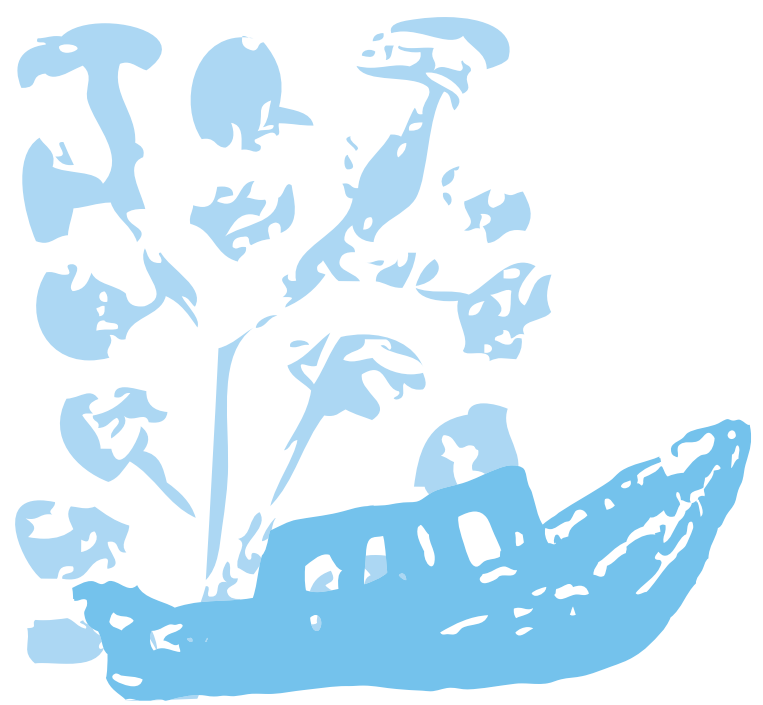

